\title{
La ressource fourragère « qui convient »
}

Conceptions et points de vue d'éleveurs des Cévennes et du Vercors

"Suitable" forage resources. Public debate and local cheeses in the Cevennes and the Vercors

\section{Martine Napoléone, Carole Chazoule et Philippe Fleury}

\section{(2) OpenEdition Journals}

Édition électronique

URL : https://journals.openedition.org/tc/7427

DOI : $10.4000 /$ tc. 7427

ISBN : 0248-6016

ISSN : 1952-420X

Éditeur

Éditions de l'EHESS

\section{Édition imprimée}

Date de publication : 1 mai 2015

Pagination : 110-129

ISBN : 9782713224874

ISSN : 0248-6016

Référence électronique

Martine Napoléone, Carole Chazoule et Philippe Fleury, "La ressource fourragère " qui convient » », Techniques \& Culture [En ligne], 63 | 2015, mis en ligne le 18 décembre 2018, consulté le 29 septembre 2022. URL : http://journals.openedition.org/tc/7427 ; DOI : https://doi.org/10.4000/tc.7427 


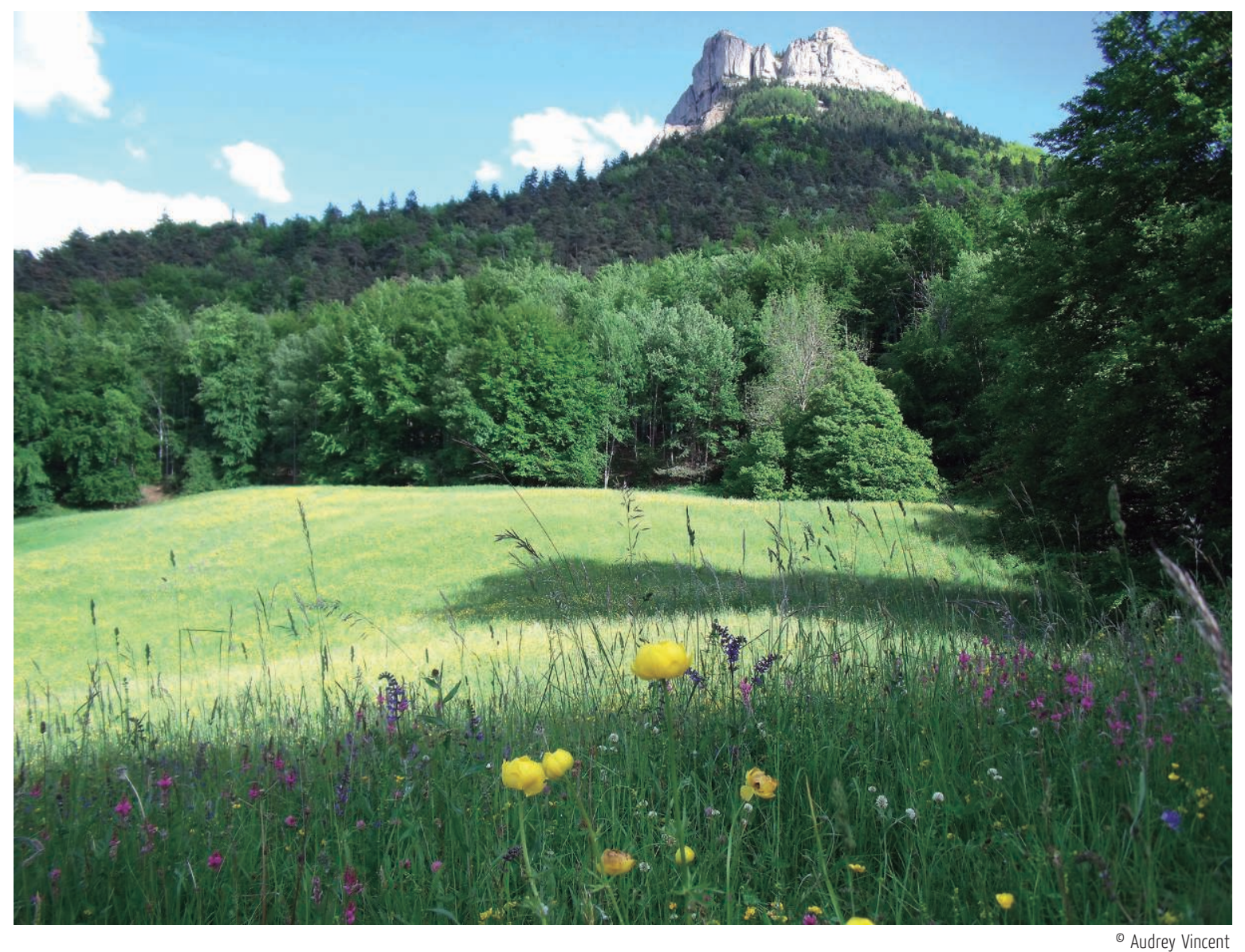




\section{LA RESSOURCE FOURRAGËRE "QUI CONVIENT »}

\section{Conceptions et points de vue d'éleveurs des Cévennes et du Vercors}

Après la seconde guerre mondiale, la production de biens alimentaires devient une priorité et constitue un véritable contrat social entre la France et son agriculture. La pensée agronomique et les modèles agricoles, encouragés par les politiques publiques, se concentrent alors sur l'espace cultivé. Le labour et l'artificialisation des espaces agricoles s'imposent comme la voie du progrès. Les agronomes proposent des variétés fourragères à haut rendement (dactyles, bromes). La productivité est gage de modernité et de technicité (Salette, J. 2006). Dans les zones d'élevage, sur les terres cultivables, la «prairie temporaire » remplace peu à peu la «prairie permanente » et les anciennes cultures vivrières. Les espaces pastoraux, les prairies naturelles et le pâturage qui portent l'image d’une agriculture appartenant au passé ne sont plus considérés comme des espaces de production. Le territoire de la France agricole se transforme en profondeur. Lagriculture et les territoires se spécialisent... Bien que çà et là, dans les zones peu propices à l'intensification, ou encore dans certains territoires enclavés, ou à forte valeur patrimoniale, perdurent des «poches de résistances » à l'homogénéisation des agricultures et des pratiques sous le coup de la «modernisation ». Tout au long de cette période, la protection de l'environnement est dissociée de l'agriculture. Elle vise à préserver des espèces rares ou des espaces emblématiques dans des réserves et parcs nationaux. Les activités agricoles ne sont pas encore appréhendées comme pouvant avoir d'effets négatifs - ou positifs- sur l'environnement et les paysages.

Jusqu'à la fin des années dix-neuf-cent-quatre-vingt, ce processus d'intensification des pratiques agricoles, jugé comme légitime par la société se poursuit. À partir des années dix-neuf-cent-quatre-vingt-dix, il commence à être interrogé par différentes crises et

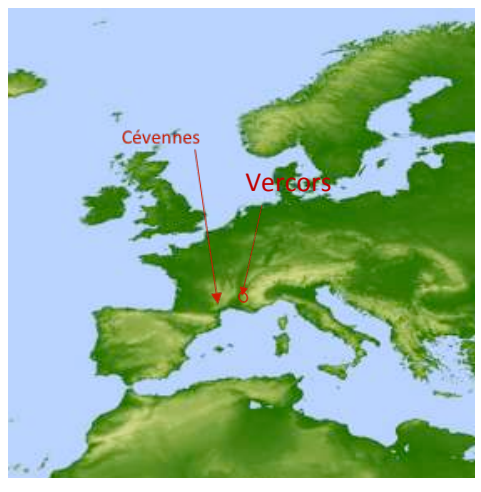




\section{Agriculture et consommation : \\ des liens étroits \\ Les modèles en agriculture ont profondément évolués depuis la guerre, \\ en lien avec les changements des formes de distribution et de consommation. \\ Les politiques publiques ont accompagné ces changements}

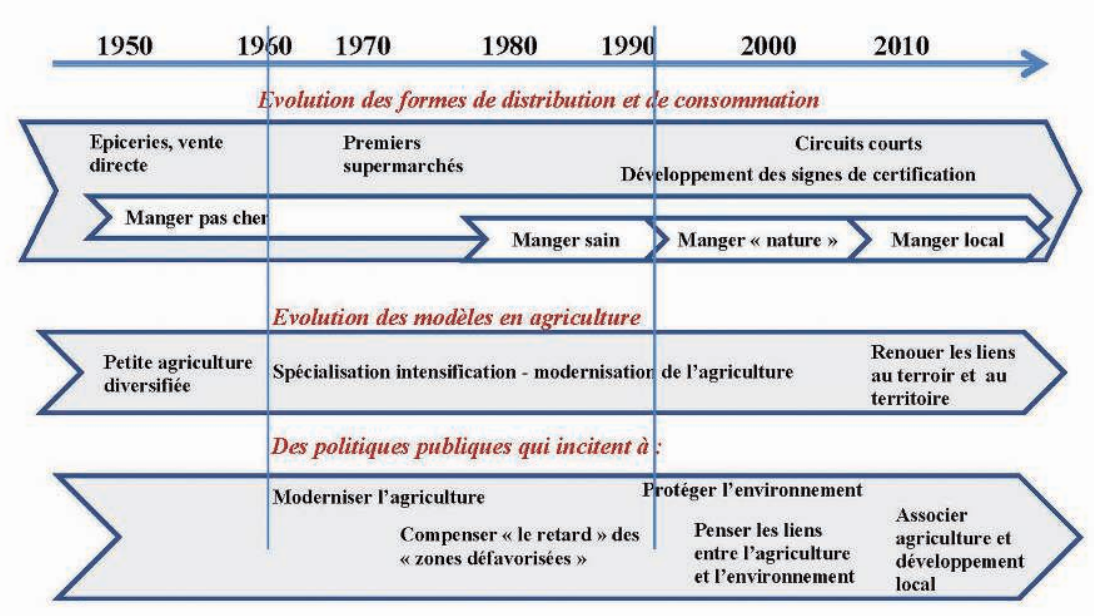

remis en cause: pollution de l'eau par les nitrates issus des engrais, pertes de biodiversité, apparition de résistances aux produits de traitements, crises sanitaires, surproduction laitière... Avec les premières mesures agro-environnementales de la Politique Agricole Commune (PAC) qui apparaissent en 1992, les agriculteurs sont encouragés à favoriser des pratiques agricoles bénéfiques à l'environnement Par ces mesures, les politiques publiques soulignent l'intérêt de s'intéresser aussi à la «nature ordinaire ", celle des campagnes et des espaces agricoles et pas seulement aux espèces emblématiques. Dans les années 2000, la montée en puissance de certaines valeurs dans la société (l'environnement, le lien au lieu, les débats sur le développement durable) et l'évolution des modes de consommation, relativisent encore la pertinence des modèles techniques considérés comme d'excellence avant les années quatre-vingt. En 2007 le Grenelle de l'environnement met sur le devant de la scène les liens forts entre environnement, agriculture, alimentation et santé. Il contribue ainsi à sensibiliser le grand public. Lanalyse de Béranger (2013) sur l'évolution de la façon dont les prairies sont perçues par les agronomes dans la seconde moitié du vingtième siècle témoigne de ces évolutions.

Pour les agriculteurs impliqués dans des démarches AOP (Appellation d'Origine Protégée), ce mouvement est vu comme un moyen de redonner de la légitimité à leur production. Jugées comme traditionnelles, les AOP sont porteuses d'une autre image de l'agriculture. Elles sont ainsi appréhendées comme capables de conserver un lien réel entre les hommes, les produits et les territoires et cela d'autant plus qu'à partir du milieu des années deux-mille, un processus est engagé pour revaloriser ce lien. Celui-ci s'inscrit, dans le cadre de l'harmonisation des cahiers des charges à l'échelle européenne, (Règlement CE n' 510/2006). Ce besoin d'un ancrage plus fort du produit au terroir par la valorisation des ressources locales conduit les responsables des AOP à se réinterroger alors sur la ressource fourragère pour nourrir le troupeau et sur l'équilibre entre celles dites naturelles et celles cultivées... d'autant plus que pour des raisons économiques, il devient nécessaire d'améliorer l'autonomie fourragère, c'est-à-dire la part de l'alimentation du troupeau qui provient de l'exploitation. La façon dont les éleveurs perçoivent l'intérêt des espaces cultivés et non cultivés, au regard de l'alimentation du troupeau, 
évolue peu à peu. La «bonne ressource fourragère » se construit dans les milieux professionnels. Elle évolue en lien avec les transformations de la société et de ses attentes. Elle porte des dimensions techniques, sociales et économiques.

Comment de nouvelles valeurs et enjeux et la mobilisation récente d'acteurs territoriaux en faveur d'une meilleure prise en compte de l'environnement dans l'agriculture font-ils évoluer les représentations des éleveurs sur ce que doit être le pâturage? Ces débats, entre éleveurs, mais aussi entre éleveurs et société locale, conduisent-ils à une évolution des normes locales quant à la manière de considérer et de conduire le pâturage et de qualifier ce qu'est une bonne ressource pour leurs animaux?

Nous abordons ces questions dans deux petites Appellations d'Origine Contrôlée: le Pélardon, fromage de chèvre des Cévennes et le Bleu du Vercors Sassenage, fromage de lait de vache provenant du Vercors dans les Alpes. Il s'agit de comprendre comment, au cours de ces 40 dernières années, se sont discutés et se discutent encore la légitimité et l'usage des types de ressources pour l'alimentation des animaux. Nous analysons en particulier pourquoi et comment les stratégies d'élaboration et de commercialisation des fromages, mais aussi de nouveaux acteurs souvent éloignés du monde de l'agriculture, s'immiscent dans ces choix et débats sur la gestion des ressources fourragères. Nous nous intéressons à trois types de ressources: les espaces « pastoraux », (landes, parcours boisés...), les prairies naturelles et les prairies temporaires. Nous croisons les regards, techniques, sociaux et économiques sur la place des ressources fourragères dans les élevages. Il s'agit ici de qualifier ce qu'est « une ressource qui convient » pour nourrir les animaux, pouvoir vivre de son travail, faire des fromages de qualité ou encore pour préserver l'environnement.

\section{Un voyage dans le temps dans deux régions fromagères: Cévennes et Vercors}

Entrons maintenant dans l'histoire des deux petites régions de montagne, de tradition fromagère, dont le produit est aujourd'hui reconnu en AOP. Ces deux petites régions ont une valeur patrimoniale et environnementale fortes, elles sont reconnues respectivement comme Parc national (PN) et Parc naturel régional (PNR).

\section{Une prairie temporaire}

Les agronomes proposent des variétés à haut rendement (dactyles, bromes). Les prairies permanentes, c'est-à-dire les prairies qui ne sont pas labourées et contiennent souvent une flore locale diversifiée sont disqualifiées au profit des prairies temporaires régulièrement labourées et ensemencées de variétés fourragères productives.

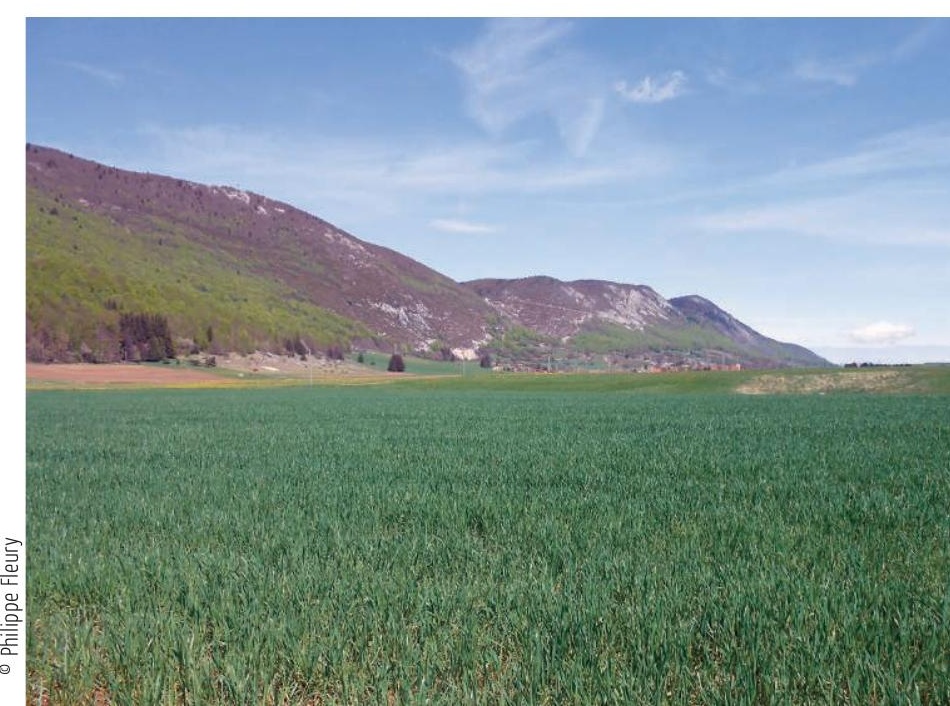


Les Cévennes et le Vercors sont des territoires d'exception, lieu et théâtre de diverses formes de résistance à travers le temps. De par leur histoire et leurs caractéristiques géographiques et physiques, ils ont d'une certaine manière échappé à l'homogénéisation des pratiques agricoles. Les tensions entre pratiques et savoir-faire traditionnels et modernisation de l'agriculture ont perduré. Ceci élargit aujourd'hui le champ des possibles en matière d'agriculture et d'élevage.

\section{Les Cévennes: un petit pays enclavé, de collines et de montagnes méditerranéennes}

Entre la plaine viticole et les causses au Sud du Massif-Central, les Cévennes sont un pays de montagne méditerranéenne, caractérisé par deux types de milieux. D’une part, des vallées étroites qui descendent des plateaux du massif central. D'autre part, des zones de piémont, plus ouvertes, constituées d'une mosaïque de collines boisées et d'espaces agricoles. Jusque dans les années soixante, prédomine en Cévennes, en piémont comme en vallée, une petite agriculture paysanne, diversifiée, d'économie domestique. À partir des années soixante, cette petite agriculture vivrière disparaît. Les espaces boisés et les parcours se ferment. S'inscrivant dans des dynamiques sociales très différentes, deux mouvements vont relancer en Cévennes une activité agricole à travers l'élevage de chèvres. Le premier s'inscrit dans la dynamique des lois de modernisation de l'agriculture et de l'élevage (1962-1966): un élevage laitier spécialisé se met en place dans deux vallées cévenoles. Le second est une des conséquences du mouvement social de 1968: des néo-ruraux s'installent en Cévennes, dans les zones pastorales et boisées délaissées par l'agriculture, notamment en piémont et développeront un élevage extensif, pastoral et fermier ${ }^{1}$. Deux formes d'élevage, reposant sur des conceptions et des valeurs différentes se mettent en place, modernisation agricole d'un côté, « retour à la terre » de l'autre. Au fil du temps ces conceptions évoluent, se rapprochent. « La ressource qui convient » est un des marqueurs de cette évolution.

\section{L'invention d'un élevage laitier moderne en vallée Cévenole}

\section{0 - 90 : la ressource c'est l'herbe cultivée sur les prés mécanisables}

Fin des années cinquante, une poignée de personnes porte le projet d'une production caprine spécialisée, comme un moyen de relance d'une activité agricole dans deux vallées. Ce projet reposera sur la création d'une petite coopérative laitière, sur l'organisation de conseils aux éleveurs et sur un modèle d'élevage performant. « 3 ha, 30 chèvres, 1 million de revenu brut $»^{2}$. Ce modèle proposé par R. Dumont aux éleveurs des vallées cévenoles, fait référence. Il repose sur la rationalisation de 3 facteurs de production: les animaux (les sélectionner), les ressources (valoriser les «terres » qui répondent à des techniques culturales), le travail (améliorer l'équipement et les chèvreries, réduire le temps de garde des troupeaux au pâturage). Forts de «l'idée (c'était) de produire au mieux sur nos petites terres », l'accent est mis sur les prés mécanisables et sur les surfaces fourragères qui peuvent être cultivées: "Sur les 3 ha, je mets de la luzerne, du brome, du sorgho pour l'été sur mes 30 ares irrigables, et du seigle immature pour l'automne ». La prairie naturelle est remplacée par des prairies temporaires. Les troupeaux mettent bas en fin d'hiver, en saison naturelle, qui 
permet au moment où les bêtes ont de gros besoins liés au pic de lactation, de bénéficier de la croissance des ressources fourragères. Le lait se fait donc « à l'herbe ». Pour limiter le travail, les animaux restent en chèvrerie. Les éleveurs s'équipent en autochargeuses pour couper l'herbe et l'apporter à l'auge aux animaux. Les bois et parcours ne sont plus utilisés. "Nous, on travaille l'herbe où ça vaut le coup ». Les éleveurs se considèrent comme des agriculteurs: « les agriculteurs travaillent les terres. Dans la forêt, c'est au forestier de le faire ». Sont donc considérées comme ressources fourragères, les espèces végétales répondant à la mécanisation de la culture et de la récolte (autochargeuse).

\section{0 - 2000 : la ressource c'est le foin}

Fin des années quatre-vingt, la collecte de la coopérative dépasse le million de litres. Les circuits commerciaux de proximité ne suffisent plus. La coopérative étend ses ventes vers la grande distribution. Laccès à ce type de marché exige de gros volumes et une régularité des livraisons tout au long de l'année. Les agriculteurs sont incités à augmenter les volumes produits et à dessaisonner leurs animaux pour produire du lait en hiver, période de manque de lait pour la coopérative. Organiser des mises bas en automne et produire du lait en hiver conduit à gérer la lactation avec du fourrage conservé, et non plus avec de l'herbe de printemps. L'augmentation des effectifs des troupeaux oblige les éleveurs à acheter du fourrage à l'extérieur. Un nouveau débat au sein de la coopérative sur les modèles de production s'instaure dans les années quatrevingt-dix. Les mises bas d'automne deviennent un signe de réussite technique et de modernité, a contrario des mises-bas de printemps qui portent le poids de la tradition. Les premiers font « du lait avec du sec », c'est-à-dire du foin. Le foin de Crau s'impose peu à peu comme ressource « bonne pour le lait ». Les seconds, restent attachés au « lait à l'herbe».

\section{L'invention d'un élevage fermier pastoral extensif, en colline}

70-90: la ressource c'est la végétation naturelle et spontanée des collines

Fin soixante-dix, arrivent en Cévennes de jeunes néo-ruraux, sans culture agricole, mais porteur d'un idéal fort de nature et de liberté. «La ruralité apparaît comme l'anti dote de la crise urbaine » (Léger et Hervieu, 1979) ... et nous pourrions rajouter du productivisme. Installés dans les zones boisées et de parcours délaissés par l'agriculture, ils vont peu à peu mettre en place des systèmes d'élevage caprins pastoraux

\section{Les Cévenes : un pays enclavé}

Un paysage essentiellement boisé. Les prés font l'objet de toutes les attentions.

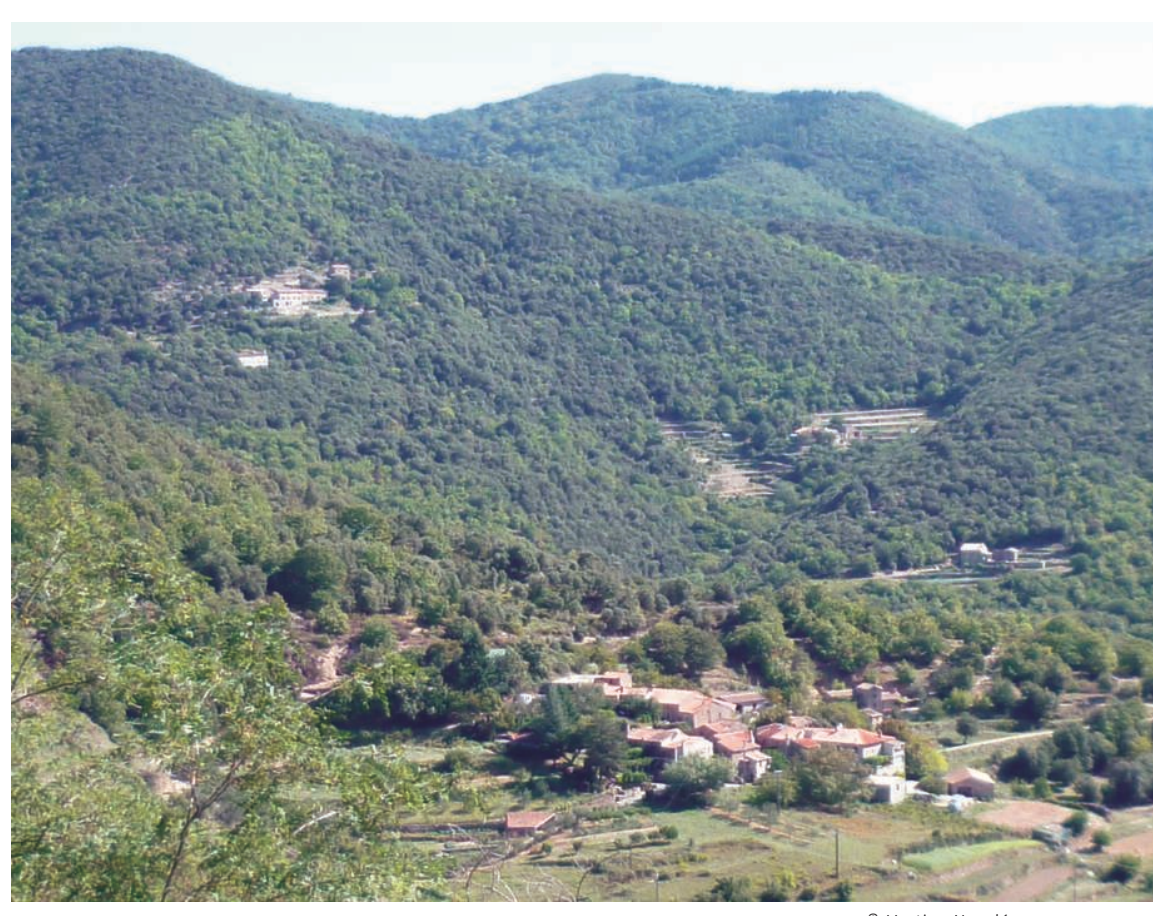

๑ Martine Napoléone 


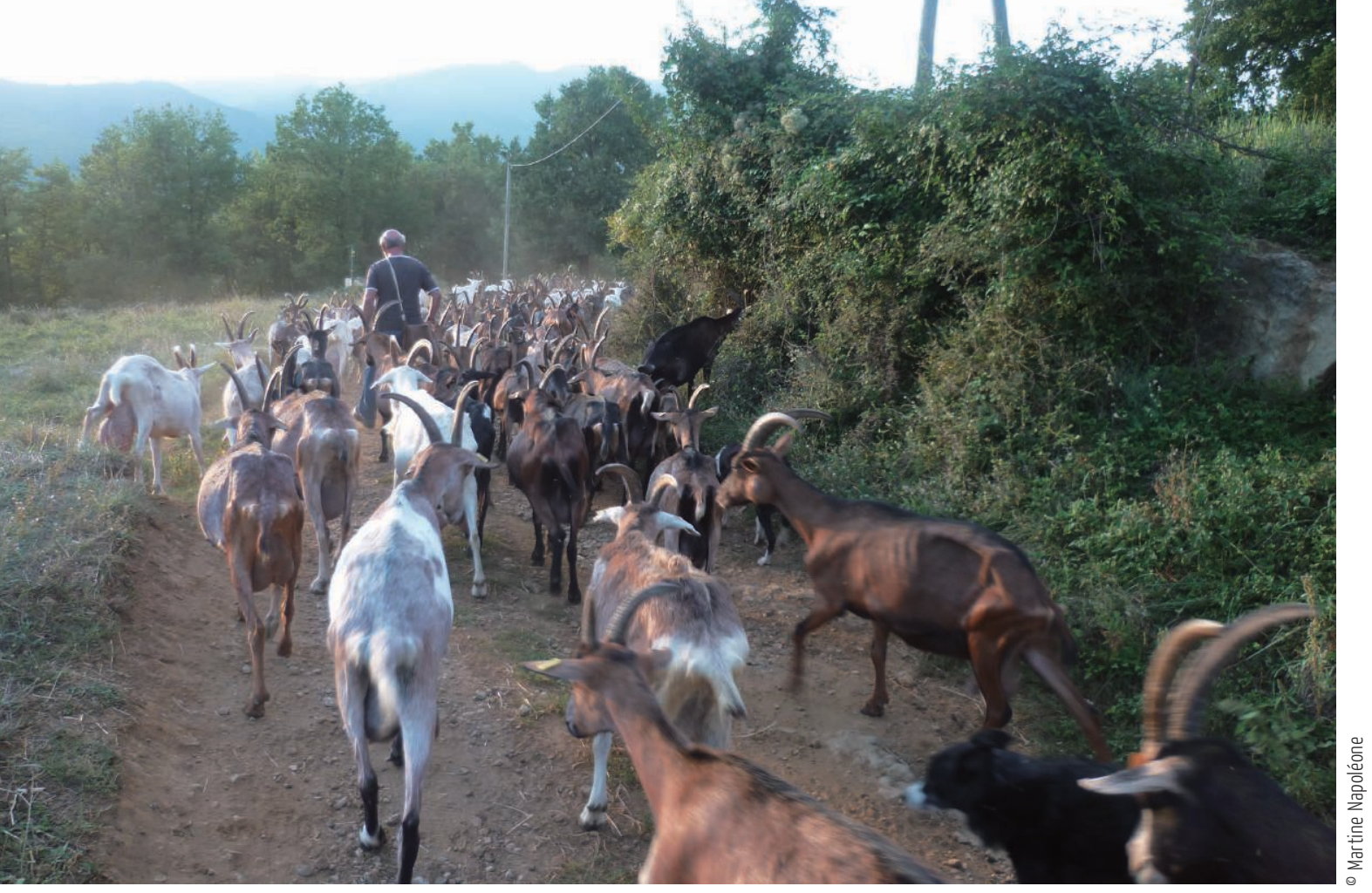

Un troupeau de chèvres et son éleveur en Cévennes

Avec la garde, l'éleveur oriente le troupeau au pâturage: « je mets l'herbe à la fin, pour finir la ration, et faire en sorte qu'elles mangent d'abord les feuilles ». extensifs. L'alimentation du troupeau repose sur le pâturage d'une diversité de ressources spontanées qui varient au fil des saisons. Une production caprine fermière se développe. Désireux d'aller au bout de la production, ils transforment eux-mêmes leur lait en fromages et les vendent directement aux consommateurs. Avec le temps, les éleveurs acquièrent de la reconnaissance locale. Ils auront de fait plus facilement accès à des prairies naturelles parfois à des terres, laissés libres lorsque leurs voisins, agriculteurs du lieu, cessent leur activité. Les ressources fourragères de ces surfaces sont utilisées en complément des espèces pastorales dans un circuit de pâturage (Meuret, 2010). Les terres peuvent aussi être semées avec des espèces spécifiques pour être pâturées à une période difficile du calendrier d'alimentation (un sorgho pour l'été, un mélange vesce avoine pour la fin du printemps...). Sauf exception, les éleveurs fermiers se voient pasteurs et non cultivateurs. Les prairies ne sont pas fauchées, mais utilisées, essentiellement, en pâturage: « on n'est pas des producteurs de foin! Notre but c'est d'essayer d'améliorer les parcours et les pâturages, pour pâturer plus ». Ces systèmes d'alimentation combinent des ressources pastorales spontanées et des ressources fourragères gérées en pâturage.

\section{Avec l'AOC: l'alimentation qui convient est en débat}

\section{0, le projet d'AOC: la rencontre de deux conceptions de l'élevage}

Pour protéger leur produit des fabrications hors de la zone, les éleveurs de la zone, qu'ils soient laitiers ou fermiers, décident collectivement d'engager en 1990 une procédure de demande de reconnaissance de leur fromage en AOC. Celle-ci est reconnue en 2000. 
Deux points de vue font consensus: «l'AOC doit être un outil juridique pour protéger le nom de notre fromage », «l'AOC est un moyen de distinguer le Pélardon d'un produit industriel ». Tous les acteurs revendiquent pour leur produit l'image et les process de la fabrication fermière et artisanale. Ils retiendront dans le cahier des charges: « lait cru, moulé à la louche, congélation du caillé interdite». La coopérative adaptera sa chaîne de transformation pour satisfaire ces clauses.

La qualification de l'ancrage au terroir à travers les pratiques d'élevage, et notamment l'utilisation du pâturage, quant à elle fait débat. Deux points de vue s'opposent. Le premier veut spécifier les conditions de production: "L'AOC est un moyen de faire reconnaître des pratiques d'élevage ». Le second, se réfère à l'origine géographique: « l'AOC est un moyen de protéger un produit lié à une région. (...) La qualification ne doit pas être un facteur d'exclusion d'un éleveur situé en zone d'appellation ${ }^{3}$. In fine, les éleveurs optent pour un compromis. La claustration permanente est interdite. L'enrubannage et l'ensilage ${ }^{4}$ sont interdits. Les troupeaux doivent sortir durant 210 jours au pâturage (180 jours en altitude). Cette clause va conduire peu à peu à l'évolution des pratiques. Les éleveurs laitiers vont ressortir leurs troupeaux au pâturage. "C'est au moins un exercice bénéfique à la santé du troupeau ».

Mais peu à peu, ils envisagent celui-ci comme une ressource alimentaire. "Le pâturage, c'est une bonne chose. J'économise le foin. Elles (les chèvres) sont mieux. Pas de fumier à lever. Moins de travail à cause des clôtures. Si j’avais su, je commençais plus tôt » explique un éleveur laitier disposant de surfaces fourragères qu'il fait pâturer depuis la création de l'AOC. Des enquêtes réalisées en 2003 chez l'ensemble des éleveurs laitiers ont montré que la grande majorité d'entre eux réduit l'apport de foin à partir du printemps. Ils le stoppent totalement en fin de printemps s'ils disposent d'assez de surfaces fourragères.

\section{Fin 2010: de nouvelles proximités entre éleveurs à travers l'ancrage au terroir}

Depuis 2010, l'augmentation des prix des fourrages, le développement des circuits de proximité, l'évolution des demandes des consommateurs, se traduisent localement par une remise en débat de l'ancrage au terroir à travers la valorisation des ressources locales. La réduction d'achat de foin et donc l'augmentation de l'autonomie fourragère devient une nécessité économique. Celle-ci passe par une augmentation de la proportion d'alimentation produite sur les surfaces utilisées par l'éleveur. En Cévennes, compte tenu des très faibles quantités de surfaces cultivables, et a contrario de la plupart des autres situations d'AOC en France, l'autonomie fourragère repose en partie sur l'augmentation du prélèvement

\section{Un pélardon...}

Chaque producteur identifie ses fromages par le logo AOP (commun à tous), et une étiquette personnalisée.

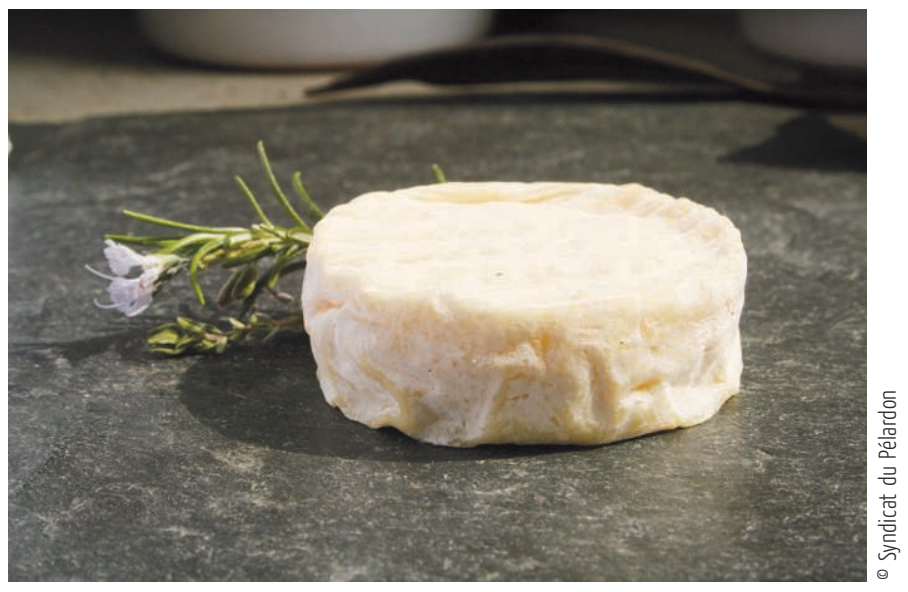

Le logo AOP du Pélardon

\| identifie des fromages dont les techniques de fabrication et d'élevage, et l'origine géographique, sont en accord avec le cahier des charges certifié par l'Institut National de I'Origine et de la Qualité (INAO). 


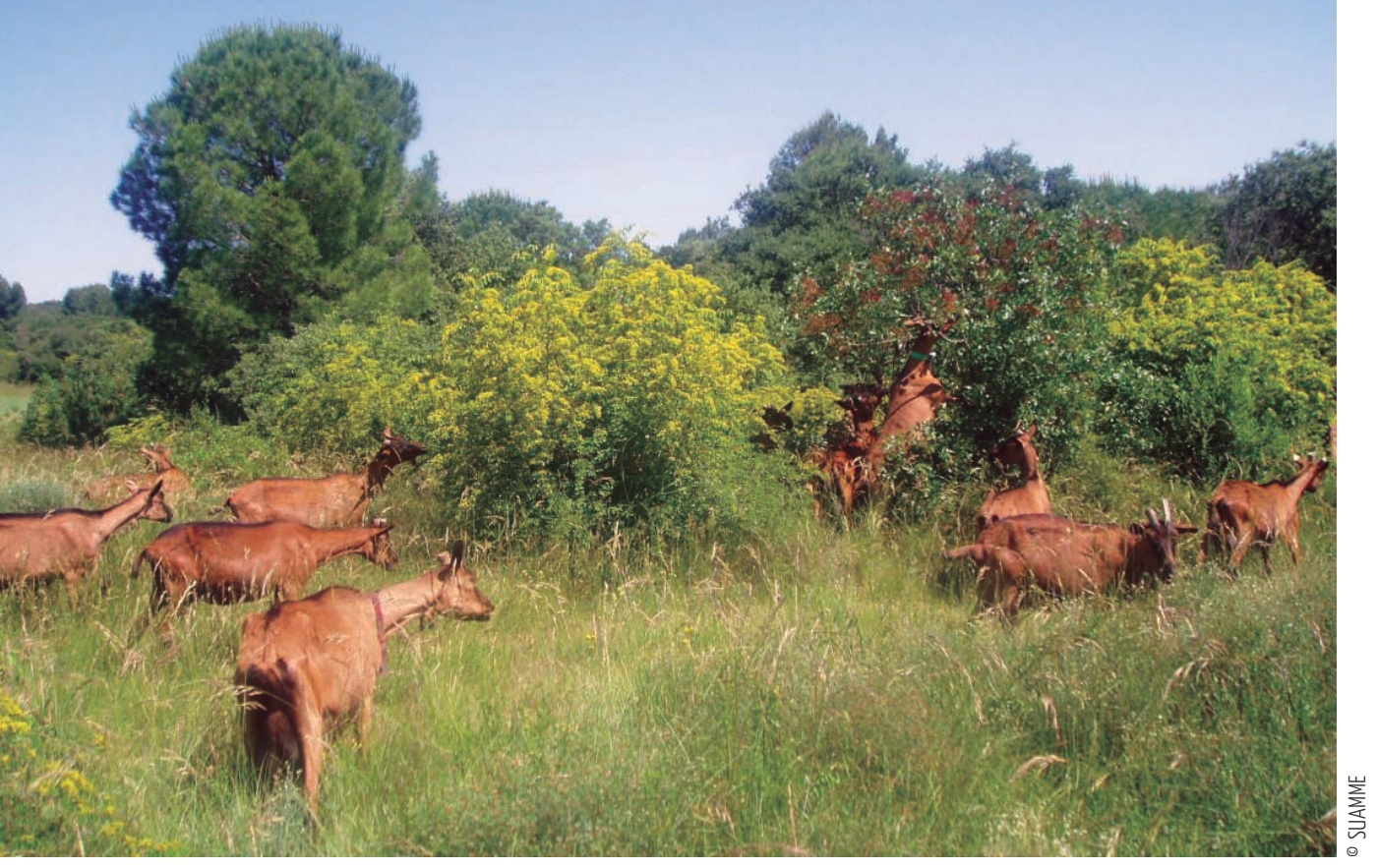

Un bon pré qui complète bien le pâturage dans les bois.

\section{Reconnaissance des paysages agro pastoraux par l'UNESCO}

C'est une reconnaissance du travail de générations d'éleveurs.Elle met en avant l'importance du maintien des milieux ouverts dans les paysages. Elle fait donc un lien entre des pratiques d'élevage, des paysages et un patrimoine territorial.

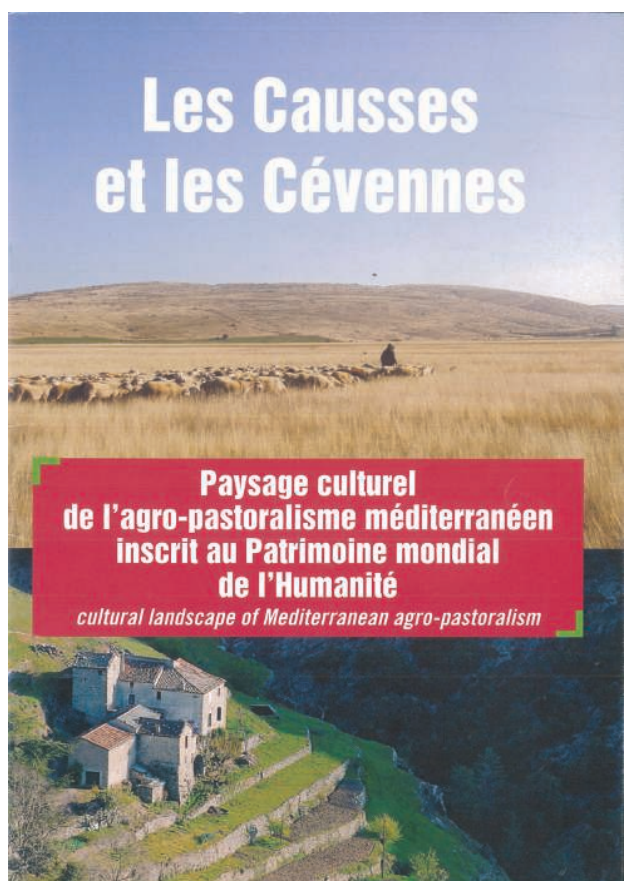

de ressources sur les milieux pastoraux, saltus, voir sylva, présentant une végétation naturelle ou semi naturelle. L'utilisation de ces milieux met en question des savoir-faire particuliers.

Ce qui fait ressource est un objet de débat entre les éleveurs dans l'AOP. Les catégories de ressources s'affinent. Les façons de les qualifier se précisent. Elles reposent sur les types de milieux, mais aussi, les types d'usages, qui, peuvent dépendre de la saison d'utilisation et du mode d'utilisation: « les landes qui démarrent tôt » « les bois frais », «les bois secs », « lesiscles (bord de rivières) pour l'été », « les prés, les sainfoins ou les luzernes, les céréales immatures, pour compléter le pâturage en rentrant à la chèvrerie ». Le pastoralisme ne porte plus l'image du passé. Il est désormais porteur de technicité.

\section{De l'ancrage au terroir à l'identité du territoire... et vice versa}

La zone du Vigan est riche de plusieurs produits de terroir: une AOC « Oignon doux des Cévennes », l'AOC « Pélardon », et la « Reinette du Vigan » pomme réputée en région. Environnement et ancrage au terroir des produits sont des attributs du territoire que les acteurs locaux et territoriaux et des filières cherchent à valoriser, en les mettant en synergie. Ils contribuent à la construction d'une image territoriale collective.

En 2012, les Causses et les Cévennes ont été inscrits au patrimoine mondial de l'humanité pour « les paysages culturels de l'agro pastoralisme méditerranéen ». «Culturel » met l'accent sur les liens patrimoniaux entre les activités d'élevage et la construction du paysage, liens qui s'étaient distanciés dans les trente glorieuses, avec d'un côté les activités de production et de l'autre celles de protection de l'environnement. Un dispositif de concertation a été mis en place pour « coordonner les initiatives de territoire en lien avec les exigences de conservation de ce patrimoine afin de développer une synergie qui contribue à la mise en valeur et à la préservation des Causses et des Cévennes ».

Avec la montée en puissance des valeurs du local et du rural, de nouvelles discussions croisées entre les acteurs de l'environnement, des territoires et les 


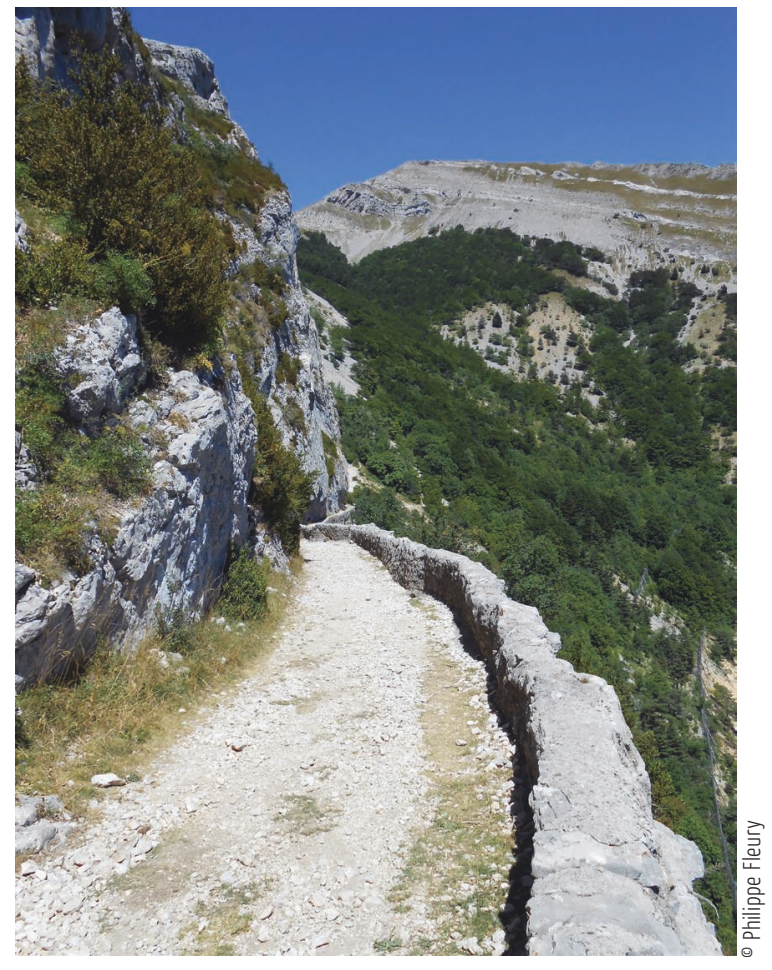

Les routes et chemins du vertige pour entrer dans le Vercors moderne en associant reconstruction des bâtiments agricoles et des laiteries et incitations à la modernisation du matériel et des cheptels (Brunier, 2013). Mais, c'est surtout à partir du début des années soixante que le mouvement d'intensification agricole prend de l'ampleur avec l'introduction de nouvelles pratiques. On assiste à une spécialisation laitière des exploitations qui jusqualors associaient, dans une logique vivrière, élevage et cultures (Allié, 2004). Les exploitations s'agrandissent et des races de vaches plus productives sont introduites: la Montbéliarde venue du Jura mais aussi la Holstein originaire de Hollande et qui est aujourd'hui la race laitière la plus présente en Europe. Le lait produit est de plus en plus commercialisé dans les circuits de la grande distribution sous forme de produits standards: yaourts, briques de lait...

Dans le Vercors, comme dans les Cévennes, les conseillers agricoles suivent les préceptes des agronomes promoteurs de la modernisation de l'agriculture. La ressource fourragère qui a de la valeur est celle qui répond aux canons du progrès technique. Un processus d'intensification des prairies se met en place, visant à maximiser à la fois la production par hectare et la valeur énergétique et azotée des fourrages (que l'on qualifie souvent de « valeur laitière ») pour accroître la production animale. Le primat est donné à la quantité en s'appuyant sur l'implantation de prairies temporaires et la fertilisation minérale qui sont préconisées de façon uniforme dans les zones fertiles alors que les secteurs de pente ou au sol rocailleux et superficiel sont abandonnés.

Les agriculteurs regroupés dans des groupements de vulgarisation agricole pour découvrir ces nouvelles techniques, s'engagent

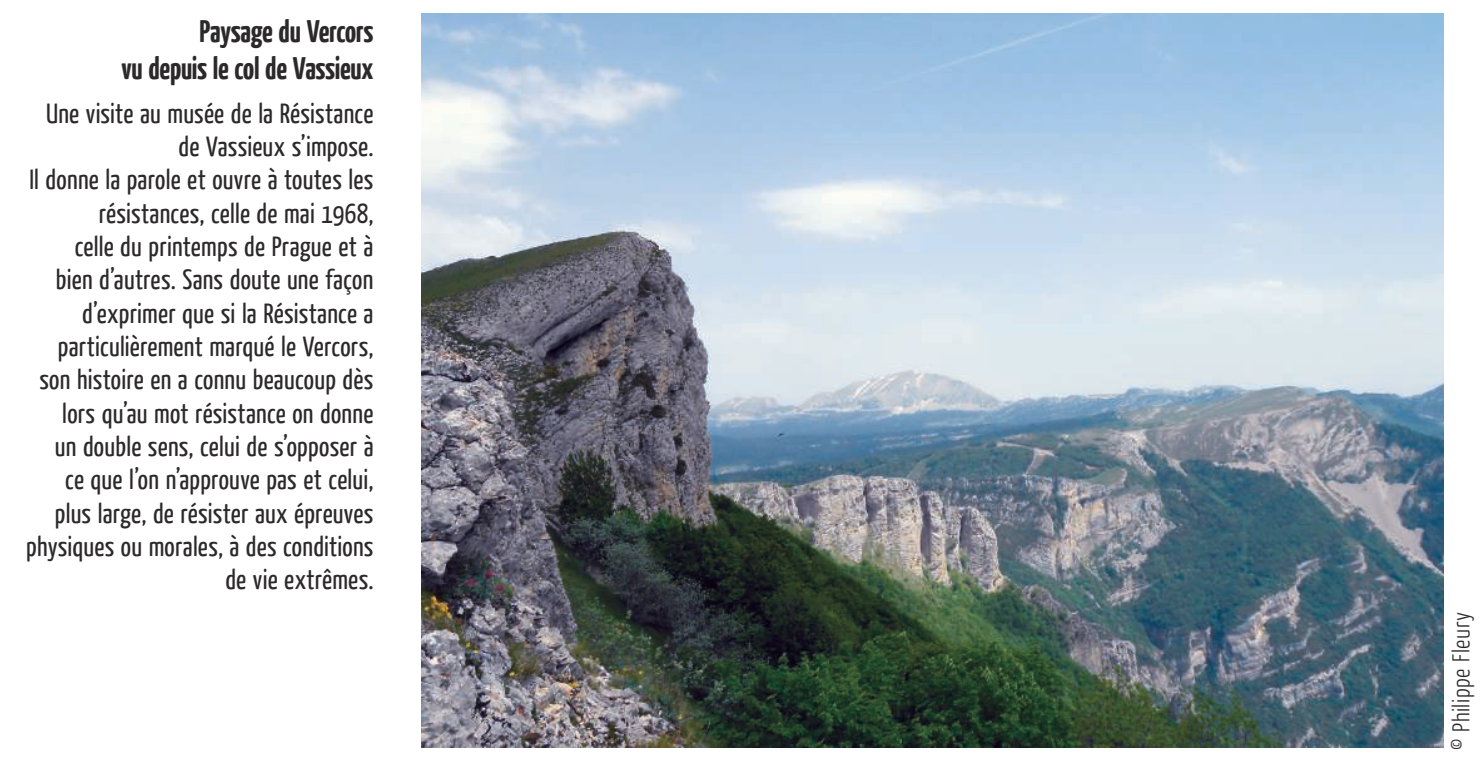


avec enthousiasme dans le mouvement. L'avenir semble assuré tant est si bien que c'est d'abord avec méfiance que les agriculteurs voient la création du Parc naturel régional (PNR) du Vercors en 1970. Le projet porté par l'État et des associations de protection de la nature leur fait craindre des mesures de protection qui bloqueraient leur développement économique. Passée cette réaction de défense, les agriculteurs préfèrent saisir la création du Parc comme une opportunité pour accompagner leur développement et créent l'APAP (Association pour la promotion des agriculteurs du Parc naturel régional du Vercors). Les relations avec le Parc s'apaisent et se stabilisent (Perret, 2003). L'APAP travaille alors étroitement avec le Parc, elle se fait porte-parole des besoins des agriculteurs et contribue à faire reconnaître l'importance de l'agriculture dans la vie économique et sociale locale. La modernisation de l'agriculture se poursuit en commun accord entre agriculteurs et parc.

\section{Les années quatre-vingt-dix: l'AOC comme modèle de développement de l'agriculture}

Dans les années quatre-vingt-dix, le modèle de plaine a montré ses limites pour maintenir l'agriculture sur le plateau du Vercors et de nombreuses exploitations ont disparu. L'idée de protéger le «bleu du Vercors Sassenage » par une AOC naît. Il s'agit de sauver la production de lait dans une perspective de développement local. L'enjeu est de conforter les exploitations agricoles mais aussi de maintenir la coopérative de collecte de lait, Vercors lait et les emplois locaux liés à l'économie laitière. Pour cela, le cahier des charges de l'AOC, c'est-à-dire sa réglementation, doit permettre de différencier le produit, d'être la garante d'un fromage de qualité pour assurer des prix de vente plus élevés et mieux rémunérer les éleveurs producteurs de lait. Pour garantir la qualité du produit il faut imposer des conditions de production, mais celles-ci ne doivent pas être trop sévères pour réunir le plus grand nombre et permettre à tous d'adhérer. Comme dans les Cévennes le compromis fut difficile et les négociations ont été longues. Tout d'abord les débats vont porter sur l'exclusion de la race Holstein. Au final, trois races de vaches restent autorisées: la Montbéliarde, l'Abondance et la Villard de Lans, la race locale dont les effectifs sont au plus bas. Une autre décision concerne l'arrêt de l'ensilage d'herbe. À la différence du foin qui est séché au sol avant d'être engrangé pour

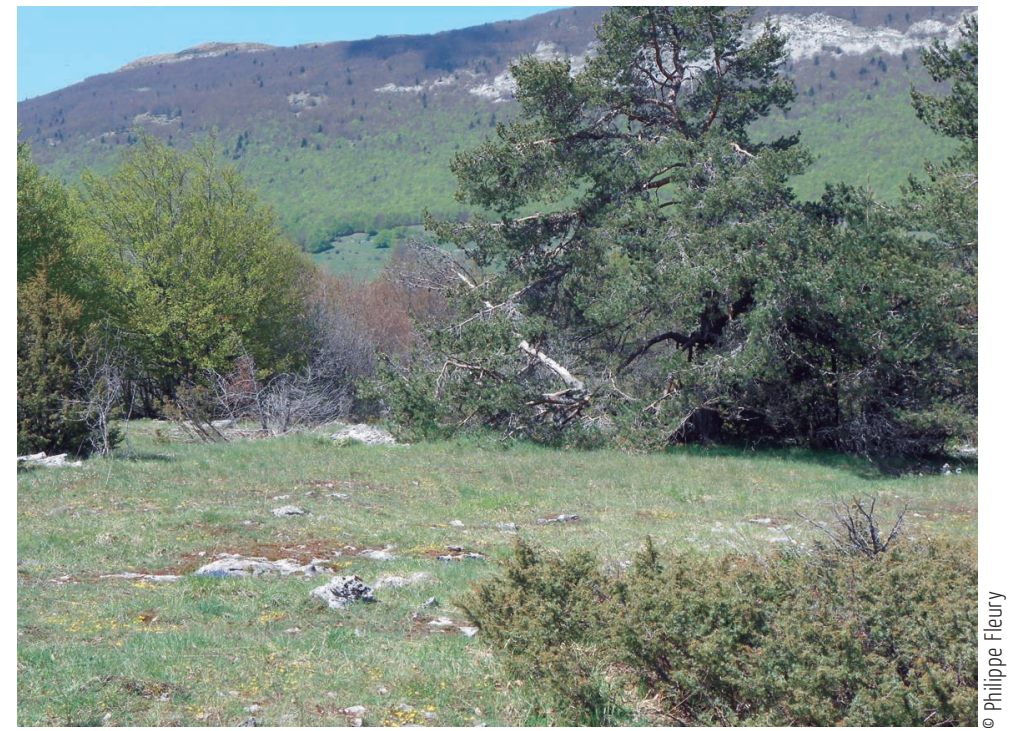

\section{Intensification des zones mécanisables et abandon des secteurs plus difficiles dans le Vercors}

Après-guerre, les zones plates et fertiles sont intensifiées avec l'abandon des cultures vivrières et l'implantation de prairies temporaires uniformes. Les éleveurs y recherchent une production fourragère importante et de haute valeur laitière.

A contrario les secteurs difficiles sont délaissés et sont peu à peu reconquis par la forêt. 
l'hiver, l'ensilage consiste à conserver l'herbe récoltée dans un silo (voir article de Doré $\&$ al. dans ce numéro). L'enrubannage, qui est un mode de conservation intermédiaire entre le foin et l'ensilage reste par contre autorisé. L'usage d'aliments concentrés et de céréales achetés à l'extérieur du territoire est aussi limité.

En 1998, l'AOC «Bleu du Vercors Sassenage » est reconnue. Son aire d'appellation s'inscrit en totalité dans le territoire du Parc Naturel Régional du Vercors auquel elle se trouve de fait liée. Dans ce contexte le choix est fait de privilégier les ressources fourragères les plus efficaces pour la production laitière. Les prairies et les pâtures deviennent les garantes du lien entre le produit et son terroir et pour assurer l'autonomie fourragère des exploitations agricoles il faut augmenter leur production tant du point de vue quantitatif que de celui de la qualité du fourrage. Les pratiques préconisées restent encore en grande partie celles de l'intensification fourragère, fauche et pâture intensive ainsi que fertilisation élevée. L'important est de ne pas trop modifier les pratiques habituelles des éleveurs afin de ne pas prendre de risque économique pour les exploitations et de mobiliser le plus grand nombre possible de producteurs dans ce projet collectif.

Le début des années quatre-vingt-dix marque aussi l'arrivée de la thématique de l'environnement dans l'agriculture. En 1991, le Vercors est un des territoires pionniers qui s'engage dans la signature de contrats entre des agriculteurs volontaires et l'État dans le cadre d'une mesure européenne agri-environnementale (Rémy, 1996). L'objectif est de préserver la biodiversité par exemple en retardant la fauche pour sauver les nichées de tétras-lyre ou préserver certaines espèces végétales rares. Il s'agit aussi d'ouvrir les pâtures à la faune sauvage en enlevant les clôtures à l'automne. Le discours qui accompagne ces prescriptions insiste sur le fait que ces nouvelles mesures peuvent renforcer le lien au territoire et amener de nouvelles pratiques valorisables dans le cadre de l'AOC. Cependant, ces mesures visent surtout majoritairement des espaces ayant peu d'importance productive, comme les prairies sèches, des clairières souvent déjà en voie d'abandon par l'agriculture. Elles ont été conçues sans les agriculteurs et ceux-ci les accueillent diversement, certains ne se privant pas de les critiquer, pour autant elles ne modifient pas leurs pratiques techniques.

\section{Depuis la fin des années 2000: agriculture et développement local}

Au milieu des années 2000 force est de constater que la production de Bleu ne se développe pas, le fromage reste peu connu et les résultats ne sont pas au rendez-vous. La coopérative qui transforme le Bleu, peine à dégager des bénéfices, les producteurs laitiers ne perçoivent pas de plus-value du fait de l'AOC: « on est parti bille en tête sur le bleu du Vercors en pensant faire chaque année une progression de X\% et puis on s'est aperçu que le bleu est très concurrencé par d'autres bleus ». Seuls les producteurs fermiers, qui sont une dizaine et produisent eux-mêmes leurs fromages à la ferme, arrivent via la vente directe, à valoriser leur lait au-delà du prix standard.

Malgré ces difficultés, l'AOC reste, pour le parc régional comme pour les agriculteurs un pivot essentiel du développement économique et rural. L'idée émerge alors de renforcer la notoriété des produits et de redonner une image positive à l'agriculture. Plusieurs décisions sont prises pour faire connaître le Bleu du Vercors Sassenage. En 2001, le Parc et les responsables du Bleu décident d'organiser une fête du Bleu. Cette fête connaît un vrai succès et depuis elle est renouvelée chaque année en Août. Elle réunit habitants et 
touristes pour fêter, connaître et apprécier le Vercors, sa culture, sa nature et ses produits. Pour compléter cette stratégie, la coopérative a depuis lancé une gamme élargie de fromages dont certains sont biologiques. Il s'agit de donner à ses produits une identité « Montagne » valorisable dans différents circuits de distribution locaux: à la ferme, dans les restaurants et boutiques locales, dans un magasin dans la ville toute proche de Grenoble.

Pour autant, des divergences concernant l'ancrage local demeurent, notamment entre producteurs laitiers et fermiers. Le fromage, sa recette, le mode d'élevage qui y est associé et avec lui les pratiques de gestion des prairies et des herbages donnent lieu à controverses. Pour les fermiers deux éléments sont primordiaux pour la qualité et la spécificité du fromage. Tout d'abord l'usage du lait cru pour la fabrication du fromage alors que cette exigence n'est pas imposée par le cahier des charges de l'AOC. Ensuite, des modes de production très ancrés au lieu qui pour eux passent par une mise en valeur de la race locale la Villardde-Lans et par une gestion extensive des pâtures et des prairies: arrêt de l'enrubannage et alimentation des animaux à partir de foin produit dans des prairies permanentes. Les producteurs fermiers rejoignent sur ce point les associations environnementalistes qui pointent du doigt le recours à l'enrubannage. Basée sur plusieurs coupes par an, cette pratique leur apparaît néfaste à la richesse de la flore et de la faune des prairies.

Pour les laitiers, ni la question de l'arrêt de l'enrubannage, ni celle du lait cru ne sont aujourd'hui au cour des enjeux de différenciation du produit: « on n'a pas cette culture du lait fromager comme en Savoie » nous dit un agriculteur responsable de la coopérative Vercors lait. Les éleveurs laitiers soulignent tous que le contexte économiquement instable freine les changements et limite la possibilité d'aller vers une AOC plus ancrée dans son territoire et imposant plus de contraintes aux agriculteurs. La question du coût de l'alimentation animale et de l'autonomie fourragère reste un frein pour les changements de pratiques. Le mouvement se poursuit donc dans le sens d'une intensification fourragère qui rassure les producteurs laitiers. Leurs objectifs prioritaires sont avant tout de réduire leurs charges fixes et d'augmenter leur revenu avant de travailler plus avant la spécificité du produit.

Depuis le début des années 2000, la gestion des prairies divise encore et toujours les producteurs fermiers et laitiers. Pour les fermiers, cette question est centrale pour affirmer la spécificité du fromage et son lien au Vercors. Elle est avec d'autres éléments comme l'usage de vaches Villardes et la fabrication au lait cru, un des symboles forts de sa différenciation sur le marché. L'AOC doit garantir des pratiques extensives même si elles impliquent une réduction du volume de production. Pour les producteurs laitiers, au contraire, seule une gestion intensive des prairies associant prairies temporaires et fertilisation élevée permet d'assurer l'autonomie fourragère et de garantir la pérennité économique des exploitations. Mais, même si cette controverse se poursuit les ressources qui conviennent se font diverses, complémentaires. Et si l'on s'accorde de plus en plus à dire que la prairie temporaire, les pâtures intensives ont leur place à proximité des exploitations ou dans les secteurs les plus plats, on s'entend aussi pour reconnaître une valeur aux ressources autrefois décriées de la prairie permanente et des pâtures peu ou pas fertilisées. Pour avancer dans cette voie, le Parc a lancé en 2010 le concours « prairies fleuries », qui récompense

\section{La fête du Bleu du Vercors Sassenage}

Elle a lieu chaque année au cœur du parc naturel régional. C'est un lieu de rencontres festives et d'échanges entre éleveurs et visiteurs.

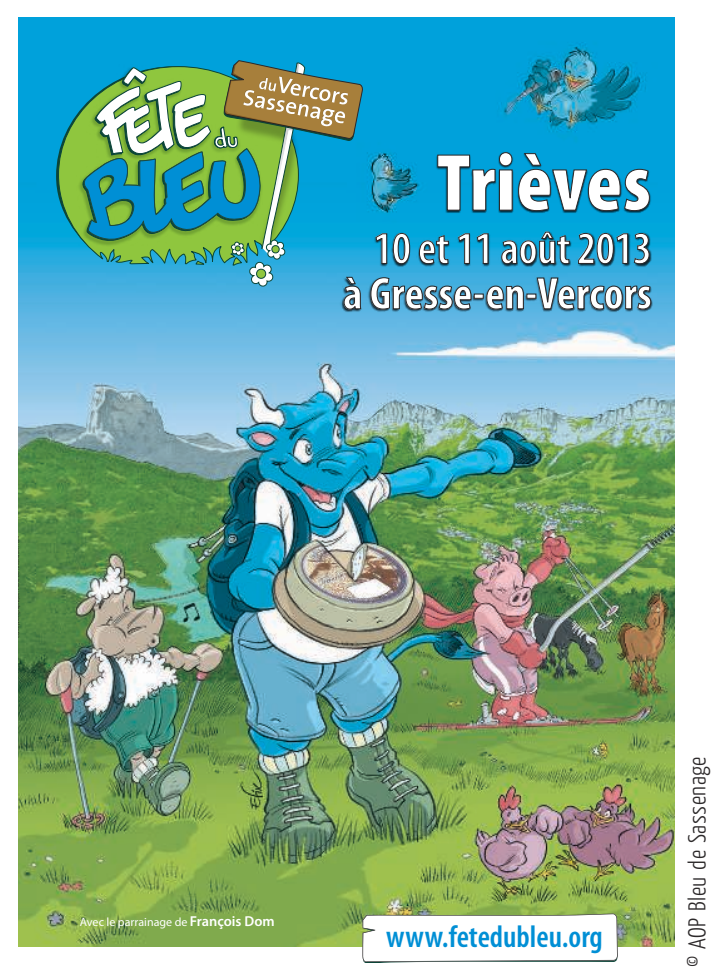




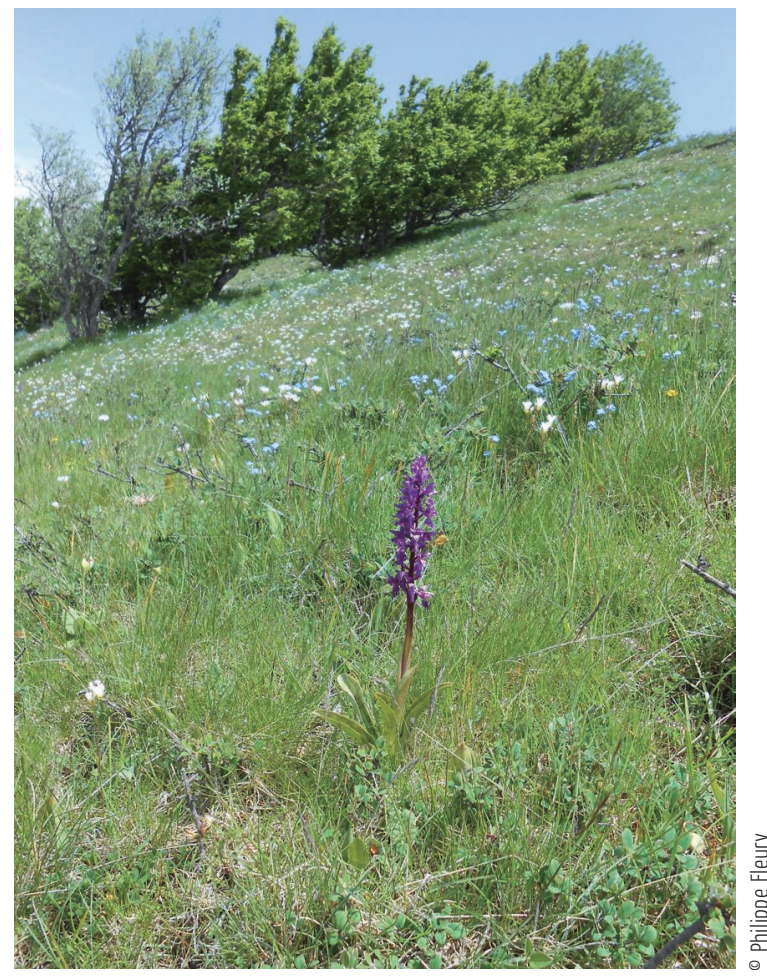

Les prairies fleuries

Les fleurs comme un marqueur de la diversité des prairies, et de pratiques culturales favorisant cette diversité. les agriculteurs ayant les prairies les plus riches en fleurs. Il joue un rôle très important pour montrer la technicité des agriculteurs dans la gestion de la biodiversité dans les prairies.

\section{Discussion}

En début du texte, nous nous demandions si - et comment- l'évolution de différentes valeurs sociétales transformait la perception des éleveurs quant à la « bonne » ressource fourragère. L'histoire de ces deux petites régions fromagères montre que cette perception se construit, se transforme et se légitime au cours du temps et au travers de controverses techniques et sociales, mais aussi au travers de l'adhésion, ou de l'opposition à un modèle de production.

\section{La ressource qui convient au troupeau: entre adhésion et opposition au modèle productif dominant}

Ainsi que Béranger (2013) l'a montré à propos de l'utilisation de la prairie, la légitimation par un groupe d'éleveurs d'une ressource fourragère plutôt qu'une autre témoigne de l'appartenance de ces éleveurs à un modèle technique. Dans les années soixante, l'ancrage des productions au terroir n'est pas à l'ordre du jour. L'enjeu est la modernisation de l'agriculture nécessaire à l'industrialisation du système alimentaire français (Rastoin et Ghersi, 2010). Pour cela, il faut intensifier les productions et augmenter les rendements afin de valoriser au mieux les facteurs de production (sol- terre- capital). Pour les producteurs, c'est un critère d'excellence technique. Les pratiques culturales se concentrent sur l'ager, c'est-à-dire l'espace cultivable. Les pâturages et les prairies peu productifs sont délaissés, avec eux les savoir-faire liés à leur gestion s'estompent. Par contre les prairies temporaires et intensives se développent sur les zones cultivables. Dans les années quatre-vingt-dix, par contre, avec les premières remises en cause du système alimentaire agroindustriel dans la société, la ressource qu'il convient de donner aux animaux est remise en débat. Les formes alternatives d'agriculture et de gestion des prairies, qui s'étaient maintenues dans certaines zones, redeviennent légitimes.

L'histoire de ces deux petites régions de montagne atteste bien de ce mouvement (entre industrialisation et territorialisation, entre agriculture « moderne » et traditionnelle »). Leur analyse nous permet d'éclairer comment ces territoires, résistent pour différentes raisons (culturelles, sociales, historiques, géographiques ou encore techniques) à l'homogénéisation des pratiques et des systèmes de production.

Ainsi, même si dans le Vercors, comme en vallées Cévenoles, l'utilisation de la prairie temporaire s'impose à tous dans les élevages laitiers, notamment pour des questions économiques, des pratiques locales de gestion des prairies naturelles perdurent. Elles s'appuient sur l'intérêt et l'attachement des agriculteurs à leur paysage et à leur territoire. Dans l'arrière-pays méditerranéens, en piémont Cévenol, les formes alternatives 
d'élevage pastoral - extensif - fermier, se sont développées en pleine période des trente glorieuses. Elles se sont inscrites localement dans des valeurs qui relevaient de la lutte contre la fermeture des milieux et des paysages, contre les risques d'incendie de forêt. La reconnaissance de ces systèmes a donc reposé sur d'autres justifications et critères que ceux des modèles dominants en agriculture, en réponse à d'autres valeurs et à d'autres enjeux locaux et sociétaux.

Force est donc de constater que dans ces territoires une diversité de pratiques, parfois de systèmes, a perduré constituant un frein à l'homogénéisation des pratiques et des savoirs.

\section{De nouveaux acteurs s'insèrent dans le débat}

Cette tendance vers des modèles de production valorisant la diversité des ressources locales se trouve renforcée aujourd'hui avec l'évolution des préoccupations sociétales. Celles-ci résolument tournées vers une prise en compte plus importante de l'environnement et du lien des produits à leur territoire sont de plus soutenues par la PAC( Politique Agricole Commune). Elles conduisent à un changement des valeurs accordées aux modèles de référence dans le monde professionnel. La gestion de la biodiversité, des paysages, de la qualité des eaux..., contribuent à définir de nouvelles valeurs et de nouveaux critères pour juger les modèles agricoles, sur leur capacité à produire, mais aussi à gérer une diversité de ressources, dans une perspective de développement durable. Certains modèles et pratiques (faire pâturer le troupeau, utiliser des landes, ou des prairies naturelles diversifiées) et les savoir-faire associés, sont perçus comme des actes techniques, associés à des savoir-faire complexes. La modernité n'est plus l'apanage des seuls modèles intensifs. L'analyse de ces deux petites régions de tradition fromagère, montre que l'évolution des valeurs sociétales, et des formes de consommation et des pratiques agricoles bousculent le sens des catégories « moderne » et « traditionnelle » et leurs frontières respectives. Les modèles - et espaces de production du coup - ne sont plus forcément « étanches »: d'un côté les modernes et de l'autre les traditionnels. Ils se complexifient, s'hybrident. Les éleveurs peuvent avoir à la fois des pratiques culturales très techniques et intensives sur certaines portions d'espaces, par exemple les prairies temporaires et des pratiques orientées sur la gestion de la diversité sur les espaces de prairies naturelles ou de parcours.

Réinvestir des zones naturelles ou semi naturelles dans une vision renouvelée de l'espace agricole?

L'étanchéité entre un espace que l'on cultive, l'ager, et les autres espaces, saltus et sylva, se fracture. Le couple ager/sylva offre de nouvelles opportunités aux éleveurs. Il s'inscrit dans de nouveaux modes de fonctionnement technique et économique combinant à la fois des ressources cultivées et des ressources naturelles et semi naturelles. Les landes et les prairies naturelles, deviennent eux aussi un espace d'alimentation pour les troupeaux, qui à certaines périodes de l'année peuvent compléter les ressources issues de l'ager ou permettre d'économiser des achats de fourrage. Poux \& al. (2009), considèrent que l'intégration du saltus dans la pensée agricole constitue l'enjeu pour une agriculture multifonctionnelle et un front politique majeur pour combiner des enjeux de production 


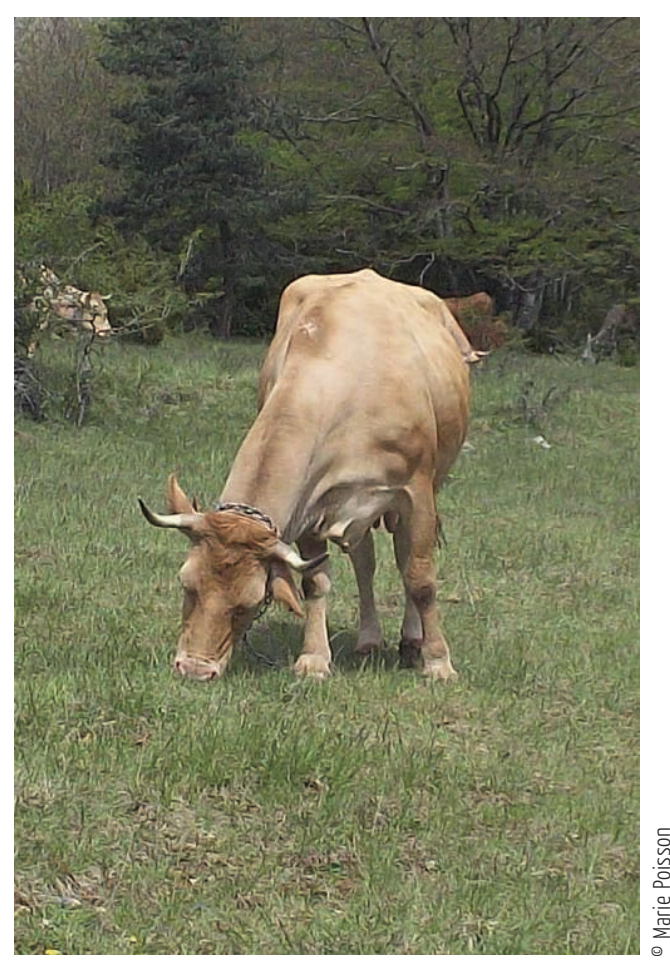

Vache de race Villard de Lans

Race originaire du Plateau du Vercors. et des enjeux environnementaux. Les débats actuels sur la redéfinition de la PAC, et la façon dont seront considérés (ou non) les divers types d'espaces pastoraux dans l'indemnité Compensatrice du Handicap Naturel (ICHN) en témoignent.

\section{L'AOP un cadre d'action collective dans lequel peuvent se redéfinir des identités professionnelles}

Dans ce débat sur la ressource qui convient, les AOP sont des lieux d'études particulièrement intéressants, pour étudier les stratégies collectives de construction d'une spécificité d'un produit par son ancrage territorial. La question des ressources fourragères et pastorales s'y pose avec acuité avec la difficulté d'arbitrer entre la recherche de l'autonomie fourragère, de l'efficacité économique des exploitations et la construction d'un lien fort au lieu passant non seulement par une part importante de ressources produites sur le territoire mais aussi par des modes de production. L'AOP est à la fois porteuse de spécificités consignées dans un décret d'appellation et un cahier des charges, et de diversité. Il y a en effet au sein d'une zone d'appellation, une diversité de territoires, de ressources végétales, de pratiques, de contexte locaux. Cette diversité, comme le soulignent Bérard et Marchenay (2007), fait partie intégrante du terroir et des usages. C'est bien cela que reconnaissent les AOP qui mettent en valeur l'aspect culturel du produit qui intègre à la fois des critères physiques, des savoirs techniques et une culture technique locale. Cette culture locale est étroitement liée à un lieu et à une communauté qui l'a produite et qui la fait évoluer. Le « savoir alimenter» le troupeau ne sera pas le même dans le Vercors ou en Cévennes. Il ne sera pas non plus homogène au sein d'une même aire d'AOP. Nous avons montré qu'entre les vallées Cévenoles et le piémont, ces savoirs sont différents et fruit d'une histoire et d'une culture technique locale. Cette diversité est la richesse de la diversité du terroir et l'essence même d'un patrimoine. L'organisation de producteurs AOP est un dispositif d'action collective. Il constitue un espace de négociation dans lequel les éleveurs peuvent redéfinir leur objectif commun, l'image qu'ils souhaitent donner au produit, ses positionnements commerciaux. Face aux enjeux actuels de réduction des intrants, de nécessité d'approfondir l'ancrage dans le cahier des charges, l'AOP est donc un cadre où se mettent en débat des pratiques, où peuvent se redéfinir des identités professionnelles.

\section{$\&$}

On s'achemine sans doute vers un nouveau contrat social entre la société et l'agriculture. Il ne s'agit plus uniquement de produire des biens alimentaires, mais aussi de maintenir et de valoriser des espaces naturels, des paysages, des savoir-faire garant 
d'un patrimoine culturel et naturel. Mais, dans les élevages du Vercors et des Cévennes comme dans ceux de nombreuses zones de montagne, l'utilisation de milieux peu anthropisés par les troupeaux revient à associer production de biens alimentaires et gestion des ressources naturelles. Le débat sur la ressource alimentaire qui convient aux animaux nous réinterroge donc profondément sur notre conception du monde et sur la pertinence d'établir des frontières aussi nettes que nous le faisons dans la culture occidentale entre nature et culture et entre modernité et archaïsme.

Ce travail a été conduit dans le cadre du projet de recherche MOUVE financé par l'Agence Nationale de la Recherche (projet ANR-2010-STRA-005-01).

\section{NOTES}

Photo d'ouverture: Prairie de fauche dans une carrière au pied du Mont Aiguille dans le Vercors

1. Éleveurs fermiers: producteur qui transforme luimême son lait en fromage et le commercialise.

2. Extrait d'un entretien réalisé en 2003, auprès d'une personne qui fût animateur CETA dans la vallée en 1960

3. Les textes en italiques ci avant sont extraits de débats au cours de l'instruction de la demande d'appellation en 1996. Ce sont des positions de représentants d'éleveurs dans ce dossier. Rappelons que dans les années quatre-vingt-dix, les pratiques d'élevage sont en général pas ou peu renseignées dans les cahiers des charges des AOC.

4. Technique de conservation du fourrage. 


\section{POUR CITER CET ARTICLE}

Napoléone, M., Chazoule, C., Fleury, P. 2015 La Ressource fourragère qui «convient ». Conceptions et points de vue d'éleveurs des Cévennes et du Vercors. In Dupré, L., Lasseur, J. \& R. Poccard-Chapuis Pâturages, Techniques \& Culture 63: 110-129.,

\section{RÉFÉRENCES}

Allaire, G. et Sylvander, B., 1997 Qualité spécifique et systèmes d'innovation territoriale, Cahier d'Économie et de Sociologie Rurales, 44 : 29-59.

Allié, L., 2004 La Gestion de l'espace dans des Parcs naturels régionaux sous pressions touristique et urbaine ou comment les acteurs bricolent du développement et de la préservation dans les massifs de Chartreuse et du Vercors? Grenoble: Faculté des études supérieures Université de Montréal/Université Joseph Fourier. (Thèse de doctorat en géographie).

Béranger, C., 2013 Les Représentations de la prairie dans la pensée agronomique de la seconde moitié du XXe siècle. Présenté en janvier 2013 au comité d'histoire de l'INRA et du CIRAD.

Bérard, L., Delfosse, C., Marchenay, P., 2004 Les « Produits de terroir»: de la recherche à l'expertise. Ethnologie française, No thématique: Géographes et ethnologues, XXXIV, 4: 591-600.

Brunier S., 2013 «Il ne s'agit pas de reconstruire mais d'édifier » Servitudes et grandeurs de la politique de reconstitution agricole dans le massif du Vercors après 1945. Histoire \& mesure, XXVIII-1 : 216-249.

Delfosse, C., (Dir.) 2007 La France fromagère (1850-1990). Paris : Boutique de l'Histoire éditions.

Du Closel, J., 1993 D’une Révolution commerciale à une autre: les grands magasins. In Culture marchande. Revue Culture technique 27 : 51-59.

Dumont, R., 1951 Voyages en France d’un agronome, M.-Th. Génin (Dir.), Paris: Librairie de Médicis.

Léger, D. \& Hervieu, B., 1979 Le Retour à la nature. Paris: édition du Seuil.

Meuret, M., 2010 Un Savoir-faire de bergers. Paris : Éditions Quae.

Perret, J., 2003 Une Communauté pour exister. In Regards croisés sur l'agriculture en Vercors. du Parc naturel régional du Vercors, (études et chroniques).

Poux, X., Narcy, J.-B., Ramain, B., 2009 Réinvestir le saltus dans la pensée agronomique moderne: vers un nouveau front eco-politique? L'Espace Politique, 9/2009-3: Fronts écologiques.

Rastouin, J.-L. \& Ghersi, G., 2010 Le Système alimentaire mondial. Concepts et méthodes, analyses et dynamiques. Paris: Quae.

Rémy, J., 1996 La Parcelle et la lisière. Eleveurs et animaux dans le parc du Vercors. Études rurales, Cultiver la nature, $\mathrm{N}^{\circ} 141-142: 85-108$.

Salette, J., 2006 La Révolution Fourragère, 50 ans après. La Révolution Fourragère et l'herbe, Fourrages, 188: 417-429.

Traversac, J.-B. (Dir.) 2011 Circuits courts. Contribution au développement régional. Dijon: Educagri Éditions. 


\section{RÉSUMÉ}

La Ressource fourragère "qui convient». Conceptions et points de vue d'éleveurs des Cévennes et du Vercors. Cet article s'intéresse au pâturage qui convient et aux ressources fourragères que l'éleveur utilise pour nourrir son troupeau. Fourrages non cultivés des prairies naturelles, des parcours ou des landes? Fourrages cultivés des prairies « temporaires »?

À partir d'une frise historique, depuis la seconde guerre mondiale, nous montrons que le pâturage qui convient évolue au cours du temps. Après la seconde guerre mondiale, les cultures s'imposaient en maître dans les modèles agricoles, face à l'enjeu de moderniser l'agriculture pour nourrir la France. Les systèmes de production et d'élevage se sont adaptés et une véritable révolution appelée fourragère s'est mise en marche. Depuis une quinzaine d'années d'autres valeurs, (qualité du produit, environnement, patrimoine...) prennent de l'importance dans la société. Il ne s'agit plus uniquement de produire des biens alimentaires, mais aussi de maintenir et de valoriser des espaces naturels, des paysages, des savoir-faire garant d'un patrimoine culturel et naturel.

Pour comprendre ces transformations, nous nous intéressons à la façon de voir le pâturage qui convient dans deux petites régions de montagne, en Cévennes et dans le Vercors, dont les fromages, le Pélardon et le Bleu du Vercors Sassenage sont reconnus AOC depuis le début des années 2000. Nous voyons que la ressource fourragère qui convient se construit, se transforme et se légitime au cours du temps et au travers de controverses techniques et sociales, mais aussi au travers de l'adhésion, ou de l'opposition à un modèle de production.

\section{ABSTRACT}

"Suitable " forage resources. Public debate and local cheeses in the Cevennes and the Vercors. Beginning with a brief overview of the situation since World War II, we show that the notion of « suitable » forage resources from the viewpoint of livestock farmers evolves over time. After World War II, agricultural models stressed the importance of planting crops in order to modernize farming to feed France. Production and livestock farming systems adapted themselves to the reality and a true « forage revolution » took place. Over the past 15 years, other values (product quality, environment, heritage, etc.) have become increasingly important to society. It is no longer a question of just producing food products, but also of maintaining and developing natural assets, landscapes, and the knowhow to ensure a cultural and natural heritage. To understand these transformations, we analyze the redefinition of « suitable » forage resources in two small mountain regions - the Cevennes and the Vercors - whose cheeses, the Pélardon and the Bleu du Vercors Sassenage, have been recognized by a Controlled Designation of Origin (AOC) since the early 2000s. We show that forage resources are built, transformed and legitimized over time and through technical and social controversies, as well as through the adhesion or opposition to production models.

\section{MOTS ClÉS}

pâturage, culture technique, nature, culture, Appellation d'Origine Protégée

\section{KEYWORDS}

grazing, technical culture, nature, culture, Protected Designation of Origin 